\title{
Combined Insulin and Bicarbonate Therapy Elicits Cerebral Edema in a Juvenile Mouse Model of Diabetic Ketoacidosis
}

\author{
KEELEY L. ROSE, CHRISTOPHER L. PIN, RENNIAN WANG, AND DOUGLAS D. FRASER
}

Children's Health Research Institute [K.L.R., C.L.P., R.W., D.D.F.], London, Ontario, Canada, N6C 2V5; Department of Physiology and Pharmacology [K.L.R., C.L.P., R.W., D.D.F.], University of Western Ontario, London, Ontario, Canada, N6A 5C1; Department of

Paediatrics [C.L.P., D.D.F.], Children's Hospital of Western Ontario, University of Western Ontario, London, Ontario, Canada, N6C 2V5; Department of Medicine [R.W.], University of Western Ontario, London, Ontario, Canada, N6C 2V5; Department of Clinical Neurological Sciences [D.D.F.], University of Western Ontario, London, Ontario, Canada, N6A 5A5; Centre for Critical Illness Research [D.D.F.], London, Ontario, Canada, N6C 2V5

\begin{abstract}
Cerebral edema in diabetic ketoacidosis (DKA-CE) occurs primarily in children and can develop during DKA therapy. The treatment factors contributing to DKA-CE remain elusive. Our objectives were to characterize an age-appropriate DKA mouse model and to determine which DKA therapies contribute to DKACE. Juvenile mice were briefly fed a high-fat diet and injected with two pancreatic $\beta$-cell toxins: streptozocin and alloxan. Severe insulin and leptin deficiencies associated with hyperosmolar ketoacidosis rapidly developed, indicating DKA. DKA mice were treated with re-hydration \pm insulin and brain water content (BWC) measured as an indicator of DKA-CE. As expected, glucose and $\beta$-OH-butyrate corrected in DKA mice that received rehydration and insulin. BWC significantly increased above control levels only in DKA mice that received combined insulin and bicarbonate therapy, indicating the development of DKA-CE. Microscopically, DKA-CE brains had perineuronal and perivascular edema, with microvacuolation in the white matter tracts. These results indicate that insulin-deficient juvenile mice develop biochemical changes that are similar to those of DKA in children. Increased BWC was observed only in DKA mice that received combined insulin and bicarbonate therapy, suggesting that rapid systemic alkalinization in the presence of insulin may contribute to DKA-CE. (Pediatr Res 61: 301-306, 2007)
\end{abstract}

$\mathrm{D}^{\mathrm{s}}$ KA is an emergency condition caused primarily by a severe lack of insulin that results in high blood glucose levels and an accumulation of acidic ketones in the blood $(1,2)$. DKA-CE is a rare but potentially devastating complication in children that occurs within the first day of therapy (3-5). The mortality associated with DKA-CE is estimated at $21-25 \%$ and significant neurologic morbidity at $10-26 \%$ (3). Despite high levels of mortality and neurologic morbidity associated with DKA-CE, the etiology of DKA-CE remains poorly understood.

Received August 1, 2006; accepted October 12, 2006.

Correspondence: Douglas D. Fraser, M.D., Ph.D., Paediatric Critical Care Medicine, Room \#C2-846, Children's Hospital of Western Ontario, London Health Sciences Centre, 800 Commissioners Road East, London, Ontario, Canada, N6C 2V5; e-mail: fraserd@lhsc.on.ca

This work was supported by grants from the Children's Health Research Institute (DDF, CP, RW), the Canadian Intensive Care Foundation (DDF), the Banting Foundation (DDF), and the Canadian Institutes of Health Research (CIHR; CP, RW). DDF is a CIHR strategic training fellow in the Canadian Child Health Clinician Scientist Program.

DOI: $10.1203 /$ pdr.0b013e318030d193
The cause of DKA-CE is a source of considerable debate $(1,6,7)$. The mechanisms proposed to elicit DKA-CE include increases in hydrostatic and/or decreases in osmotic pressure, increases in blood brain barrier permeability, loss of cerebral vascular autoregulation and subsequent changes in cerebral blood flow, production of intracellular osmoles in brain cells, and/or intracranial acidosis. Despite an abundance of theories on the pathophysiology of DKA-CE, there is little evidence to support any particular mechanism.

Clinical studies have linked newly diagnosed diabetes, young age, low blood $\mathrm{CO}_{2}$, high blood urea nitrogen, and administration of bicarbonate to the development of DKA-CE $(5,8,9)$. While these epidemiologic studies may identify children at risk for developing of DKA-CE, animal translational studies will provide insight into the cellular mechanisms contributing to DKA-CE. To date, animal studies on DKA-CE have been limited by a lack of age-appropriate animal models. The aims of this study were to characterize a juvenile mouse model of DKA and to determine which DKA therapeutic manipulations may contribute to DKA-CE.

\section{MATERIALS AND METHODS}

This study was approved by the University of Western Ontario Animal Care Committee in accordance with the Guidelines of the Canadian Council on Animal Care.

Mouse model of DKA. Juvenile male C57BL/6 mice, aged 20-21 d, were fed a high-fat diet (Research Diets Inc., New Brunswick, NJ) for $14 \mathrm{~d}$. Mice were then fasted for $16 \mathrm{~h}$ (10), weighed, and randomly assigned to either control or DKA groups. Each mouse in the DKA group received a $0.25 \mathrm{~mL}$ intraperitoneal (i.p.) injection containing STZ (200 mg/kg) and ALX (200 $\mathrm{mg} / \mathrm{kg}$ ). STZ/ALX was dissolved by cold citrate buffer $(10 \mathrm{mM} ; \mathrm{pH} 4.5)$ in glass immediately before injection. Control mice received the same volume of citrate buffer only. Glucose and $\beta$-OH-butyrate levels were measured from tail vein blood $72 \mathrm{~h}$ postinjection with a glucometer (Lifescan, Burnaby, BC, Canada) (11) and ketone meter (Abbot Laboratories, Bedford, MA), respectively. Serum $\beta$-OH-butyrate measured from DKA patients with this ketone meter correlate with laboratory $\beta$-OH-butyrate values $(12,13)$.

Blood chemistry. Following anesthesia with an i.p. injection of ketamine $(85-150 \mathrm{mg} / \mathrm{kg})$ containing xylazine $(8-15 \mathrm{mg} / \mathrm{kg})$, blood was obtained by intracardiac puncture for analysis of blood electrolytes, urea, and osmolality. Blood gases were not measured as the deep anesthesia required for intracar-

Abbreviations: ALX, alloxan; BWC, brain water concentration; DKA, diabetic ketoacidosis; DKA-CE, diabetic ketoacidosis cerebral edema; H\&E, hematoxylin and eosin; PFA, paraformaldehyde; STZ, streptozocin 
diac blood sampling resulted in altered respiratory rates and hence, artifactual changes in $\mathrm{CO}_{2}$ and $\mathrm{pH}$.

Pancreatic $\boldsymbol{H} \& \boldsymbol{E}$ staining and immunohistochemistry. For H\&E staining, $10 \mu \mathrm{m}$ pancreatic cryosections were fixed in cold acetone for $5 \mathrm{~min}$ then rinsed in water. Sections were exposed to CAT hematoxylin for $2 \mathrm{~min}$, and then rinsed in water for $45 \mathrm{~s}$. Sections were placed in Tacha's bluing solution for $30 \mathrm{~s}$, and then rinsed with water for $10 \mathrm{~min}$. Finally, sections were dipped in eosin Y three times before dehydration in ethanol and xylene. Slides were mounted with Permount (Fisher Scientific, Nepean, ON, Canada). For immunohistochemistry, pancreatic cryosections were thawed and then fixed in $4 \%$ paraformaldehyde (PFA) for $15 \mathrm{~min}$. Following a wash in PBS, cells were permeabilized with $0.1 \%$ Triton X-100 for $10 \mathrm{~min}$ and then blocked with 5\% BSA and $10 \%$ goat serum for $30 \mathrm{~min}$. Pancreatic sections were incubated with guinea pig anti-insulin (1:50) and mouse anti-glucagon (1:2000) overnight at $4^{\circ} \mathrm{C}$. After several PBS washings, sections were incubated with goat antimouse conjugated to FITC (1:50) and goat anti-guinea pig conjugated to TRITC (1:50) for $2 \mathrm{~h}$ at room temperature. Slides were washed in PBS and then mounted in Vectashield (Vector Laboratories, Burlingame, CA).

Insulin and leptin ELISA. Pancreatic and serum insulin were measured using an ultrasensitive mouse insulin ELISA kit (ALPCO Diagnostics, Windham, $\mathrm{NH}$ ). Pancreatic insulin was determined simultaneously with pancreatic DNA and normalized as nanograms per microgram DNA. Serum leptin was measured using a mouse/rat leptin ELISA kit (ALPCO Diagnostics).

DKA treatment protocols. DKA was established by glucose and $\beta-\mathrm{OH}-$ butyrate testing, followed by administration of one of four treatment protocols: 1) $3 \mathrm{~mL}$ of $77 \mathrm{mM} \mathrm{NaCl}$, 2) $3 \mathrm{~mL}$ of $77 \mathrm{mM} \mathrm{NaCl}$ with insulin, 3) $3 \mathrm{~mL}$ of $77 \mathrm{mM} \mathrm{NaHCO}$, 4) $3 \mathrm{~mL}$ of $77 \mathrm{mM} \mathrm{NaHCO}$ with insulin. Intravenous access is exceedingly difficult in these small, dehydrated mice. Thus, rehydration solutions \pm insulin was given as a single i.p. injection allowing for slow systemic adsorption. The concentration of insulin (1.0 U R, $1 \mathrm{U} \mathrm{NPH})$ administered to mice is exaggerated to account for reduced human insulin responsiveness in rodents (14). All mice were killed $2 \mathrm{~h}$ posttreatment for analysis of serum biochemistry and DKA-CE.

Brain water content $(\boldsymbol{B} W \boldsymbol{C})$. Mice were euthanized and the brains were rapidly excised and immediately weighed. The brains were placed in an oven at $60^{\circ} \mathrm{C}$ for $5 \mathrm{~d}$, and then reweighed. Brain weight was found to be constant at this time with no further decreases. BWC was calculated with the following formula: $\mathrm{L} / \mathrm{kg}($ dry weight $)=[($ wet mass - dry mass $(\mathrm{mg})) \times(1 \mathrm{~mL} / 1000 \mathrm{mg}) \times$ $(1 \mathrm{~L} / 1000 \mathrm{~mL})] /$ dry mass $(\mathrm{kg})$. Increases in BWC have been shown previously to correlate well with both elevations in intracranial pressure and abnormalities on brain histopathology (15).

Neuropathological analysis. Deep anesthesia was induced with ketamine and xylazine, and mice were perfused with $4 \%$ PFA in the left ventricle via midline thoracotomy. Brains were removed and immersed in PFA for $24 \mathrm{~h}$ at $4^{\circ} \mathrm{C}$, then rinsed in PBS two to three times a day for $3 \mathrm{~d}$. Brains were immersed in $70 \%$ ethanol for $24 \mathrm{~h}$ before paraffin embedding and sectioning. H\&E staining was conducted as noted above. Neuropathological findings were identified by two blinded observers.

Materials and data analysis. Unless otherwise stated, all chemicals were obtained from Sigma Chemical Co. (St. Louis, MO). Statistical significance $(p<$ 0.05) was assessed with SigmaStat (Systat Software, San Jose, CA). Data are presented as mean \pm SEM.

\section{RESULTS}

Of 279 mice injected with STZ/ALX, 228 mice had sufficient DKA for further experimentation (glucose $\geq 20 \mathrm{mM}$; $\beta$-OH-butyrate $\geq 2.0 \mathrm{mM}$ ). Biochemical analysis of blood from these DKA mice $72 \mathrm{~h}$ postinjection of STZ/ALX showed significantly elevated glucose, $\beta$-OH-butyrate, urea, and osmolality (Table 1). Serum glucose and osmolality positively correlated (correlation coefficient $=0.847, p<0.05 ; \mathrm{R}^{2}=$ $0.72 ; n=37)$. DKA mice also had significantly decreased sodium, chloride, and bicarbonate (Table 1). Serum bicarbonate and $\beta$-OH-butyrate negatively correlated (correlation coefficient $\left.=-0.651, p<0.05 ; \mathrm{R}^{2}=0.42 ; n=37\right)$. $\beta$-OHbutyrate $>2.0 \mathrm{mM}$ correlated with a bicarbonate $\leq 14 \mathrm{mM}$. Serum creatinine levels from DKA mice were 24-54 $\mu \mathrm{M}$ $(n=3)$, indicating normal renal function (16).

DKA mice were lethargic and anorexic, and wet patches were observed in their cages due to presumed osmotic diure-
Table 1. Blood biochemistry values from control and DKA (STZ/ALX) mice at $72 \mathrm{~h}$ postinjection

\begin{tabular}{lcc}
\hline & Control & DKA \\
\hline Sodium $(\mathrm{mmol} / \mathrm{L})$ & $147 \pm 1$ & $137 \pm 1^{*}$ \\
Potassium $(\mathrm{mmol} / \mathrm{L})$ & $4.3 \pm 0.2$ & $4.1 \pm 0.3$ \\
Chloride $(\mathrm{mmol} / \mathrm{L})$ & $113 \pm 1$ & $104 \pm 1^{*}$ \\
Glucose $(\mathrm{mmol} / \mathrm{L})$ & $10.0 \pm 0.3$ & $30.3 \pm 0.6^{*}$ \\
Bicarbonate $(\mathrm{mmol} / \mathrm{L})$ & $16.5 \pm 0.4$ & $9.8 \pm 1.2^{*}$ \\
Urea $(\mathrm{mmol} / \mathrm{L})$ & $6.3 \pm 0.3$ & $28.6 \pm 5.7^{*}$ \\
Effective osmolality (mOsmol) & $312 \pm 1$ & $362 \pm 9^{*}$ \\
$\beta$-OH-butyrate (mmol/L) & $0.20 \pm 0.03$ & $4.20 \pm 0.19^{*}$ \\
\hline
\end{tabular}

All groups represent an $n=27-30$, except for bicarbonate, where $n=$ 17-22. Effective osmolalities were calculated by $\left[\mathrm{Na}^{+}(\mathrm{mmol} / \mathrm{L}) \times 2\right]+$ glucose $(\mathrm{mmol} / \mathrm{L}) . *$ Significantly different compared with control according to Mann-Whitney rank sum test $(p<0.001)$. Blood gases were not measured as the deep anesthesia required for intracardiac blood sampling resulted in altered respiratory rates and hence, artifactual changes in $\mathrm{CO}_{2}$ and $\mathrm{pH}$.

sis. The average weights of control and DKA mice $72 \mathrm{~h}$ postinjection were significantly different at $23.7 \pm 0.2 \mathrm{~g}(n=$ $88)$ and $18.5 \pm 0.2 \mathrm{~g}(n=165)$, respectively $(p<0.001$, Mann-Whitney rank sum test). Control mice gained $2.1 \pm 0.1$ $\mathrm{g}$ over the $72 \mathrm{~h}$, while the DKA mice lost an average of $3.0 \pm$ $0.1 \mathrm{~g}(p<0.001$, Mann-Whitney rank sum test).

Pancreatic sections from DKA mice confirmed a reduction in insulin containing $\beta$-cells ( $n=3$ mice/group). H\&E staining revealed morphologically normal islets in pancreatic sections from control mice (Fig. 1A), whereas pancreatic islets from DKA mice showed signs of hyperplasia with numerous small cells forming disorganized islets (Fig. 1B). Pancreatic islets from control mice stained well for insulin and glucagon (Fig. 1C). In contrast, DKA mice had pancreatic islets which stained weakly for insulin, but maintained strong staining for glucagon (Fig. 1D). Destruction of pancreatic $\beta$-cells in DKA mice correlated with significantly decreased insulin [pancreatic-DKA, $0.2 \pm 0.1 \mathrm{ng} / \mu \mathrm{g}$ DNA; control, $7.2 \pm 1.5 \mathrm{ng} / \mu \mathrm{g}$ DNA, $n=6-12$ (Fig. $1 E$ ); serum-DKA, $0.02 \pm 0.003$ nmol/L; control, $0.32 \pm 0.07 \mathrm{nmol} / \mathrm{L}, n=6-10$ (Fig. $1 F)$ ].

Leptin is a circulating peptide released by adipocytes and involved in short-term energy homeostasis. Serum leptin is reduced in children with type-1 diabetes presenting with DKA (17) and serum leptin was also significantly decreased in DKA mice (DKA, $0.4 \pm 0.1 \mathrm{ng} / \mathrm{L}$, control, $2.3 \pm 0.3 \mathrm{ng} / \mathrm{L}, n=5-6$, $p<0.001, t$ test).

DKA mice had a serum glucose concentration of $31.4 \pm 0.3$ $\mathrm{mM}$ and $\beta$-OH-butyrate concentration of $4.1 \pm 0.1 \mathrm{mM}$ (Fig. $2 ; n=23-30$ mice/group). Treatment with saline rehydration did not significantly alter glucose $(30.6 \pm 0.8 \mathrm{mM})$ or $\beta$ - $\mathrm{OH}$ butyrate $(4.0 \pm 0.2 \mathrm{mM})$. Administration of a bicarbonate solution resulted in mildly elevated glucose $(32.4 \pm 0.4 \mathrm{mM})$ and $\beta$-OH-butyrate $(5.0 \pm 0.1 \mathrm{mM})$. In contrast, the addition of insulin to the saline rehydration solution resulted in a significant reduction in glucose $(15.5 \pm 2.4 \mathrm{mM})$ and $\beta$-OHbutyrate $(2.7 \pm 0.3 \mathrm{mM})$. Treatment with both a bicarbonate rehydration solution and insulin also resulted in a significant reduction in glucose $(7.3 \pm 1.2 \mathrm{mM})$ and $\beta$-OH-butyrate ( $3.2 \pm$ $0.3 \mathrm{mM}$ ). Comparison of all groups for glucose concentration at $2 \mathrm{~h}$ posttreatment showed that the rehydration only groups (saline or bicarbonate) were significantly different to those 

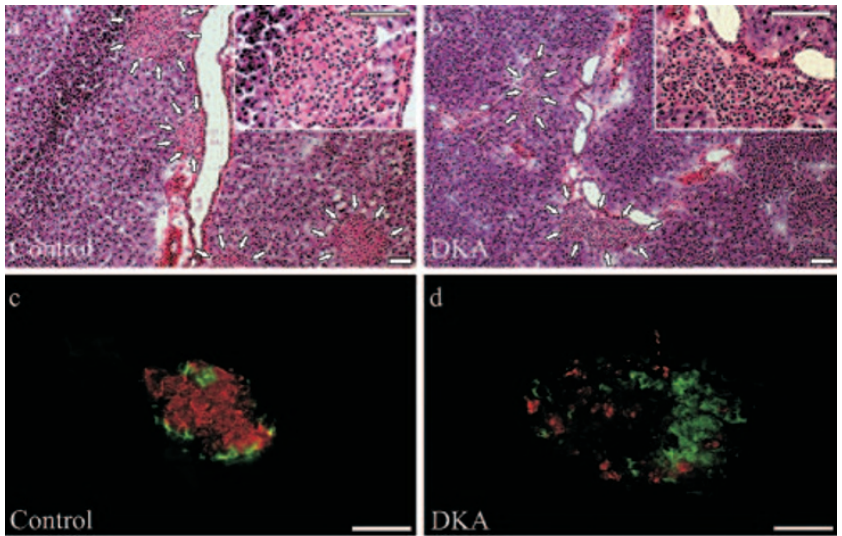

e
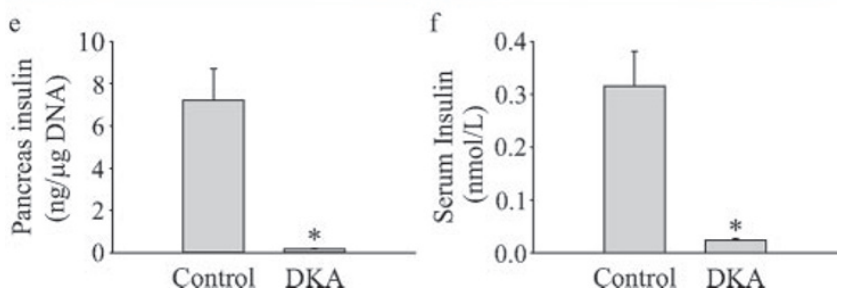

Figure 1. DKA is caused by insulin deficiency. Seventy-two hours after STZ/ALX injection, pancreata were examined for islet morphology (H\&E: $a$, $b$ ) and insulin expression (immunofluorescence: $c, d) .(a, b)$ DKA mice had disorganized islets with cellular hyperplasia. Arrows indicate islets. Insets show enlarged views of islets. $(c, d)$ A dramatic reduction in insulinexpressing $\beta$-cells was observed in DKA mice $(r e d)$. This trend was not observed in glucagon-expressing $\alpha$-cells (green). Magnification bars $=70$ $\mu \mathrm{m}(a, b)$ and $60 \mu \mathrm{m}$ (insets and $c, d)$. (e) The plot shows decreased pancreatic insulin in DKA mice determined with ELISA, and normalized as ng/ $\mu \mathrm{g}$ DNA ( ${ }^{*} p<0.001$, Mann-Whitney rank sum test). $(f)$ The plot shows decreased serum insulin in DKA mice determined with ELISA $\left({ }^{*} p<0.001\right.$, Mann-Whitney rank sum test).
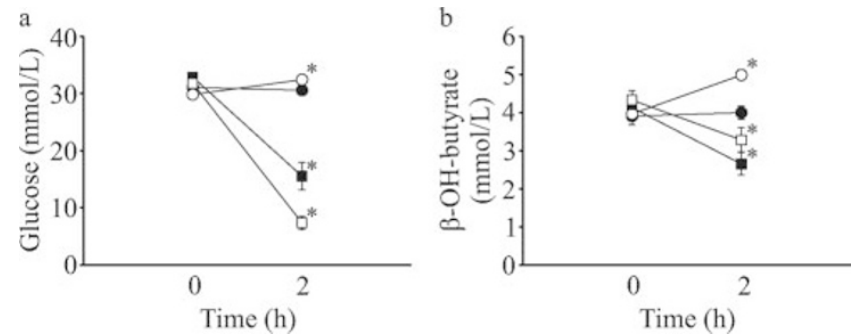

Figure 2. Treatment of DKA mice with fluid rehydration + insulin significantly reduced serum glucose $(a)$ and $\beta$-OH-butyrate $(b)$. DKA treatments: $(1)$ $\mathrm{NaCl}(\bullet-\bullet),(2) \mathrm{NaHCO}_{3}(\bigcirc-O)$, (3) $\mathrm{NaCl}+$ insulin $(\square-\square)$, or (4) $\mathrm{NaHCO}_{3}+$ insulin (-ם). Blood glucose and $\beta$-OH-butyrate levels in DKA mice injected with $\mathrm{NaCl}$ alone did not significantly differ from control. In contrast, blood glucose and $\beta-\mathrm{OH}$-butyrate levels significantly decreased in both groups that received rehydration and insulin $\left({ }^{*} p<0.001\right.$, paired $t$ test or Wilcoxon rank signed test).

rehydration groups that also received insulin $(p<0.05$, ANOVA with Dunn's multiple comparison procedure). There were no significant differences in glucose concentration between groups that received saline + insulin or bicarbonate + insulin. Comparison of all groups for $\beta$-OH-butyrate concentration at $2 \mathrm{~h}$ posttreatment showed that the bicarbonate rehydration only group was significantly different from all other treatment groups $(p<0.05$, ANOVA with Dunn's multiple comparison procedure).
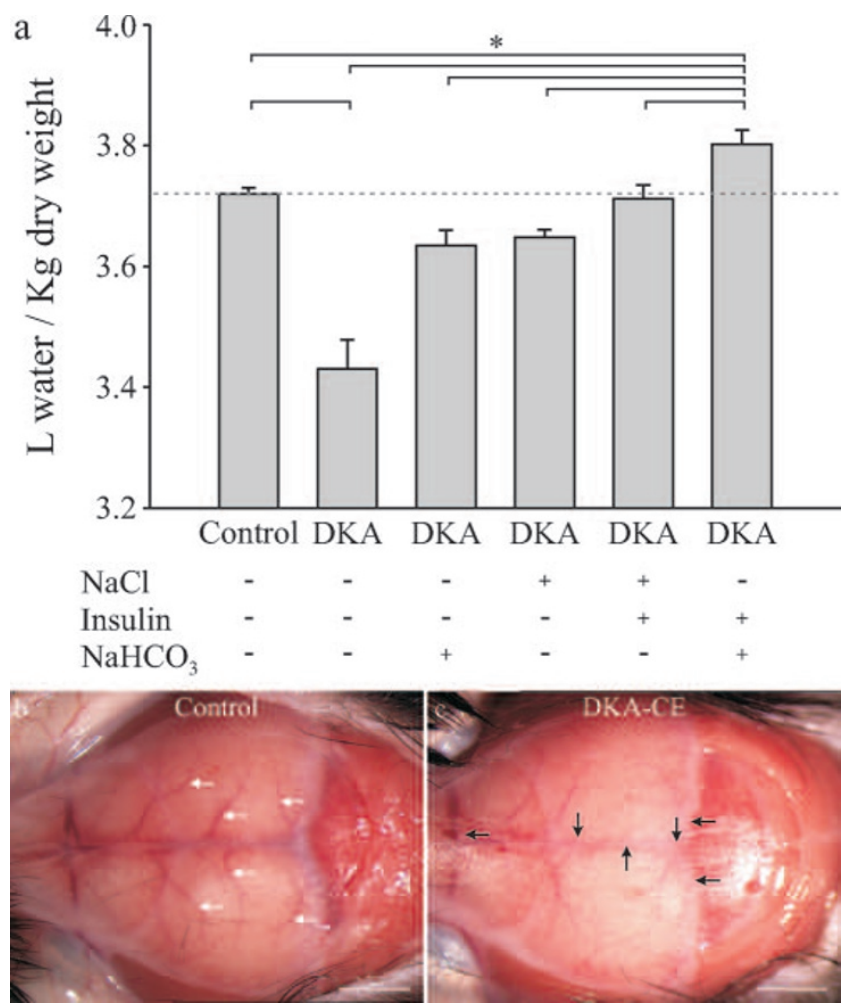

Figure 3. BWC is significantly increased in DKA mice after treatment with bicarbonate + insulin, indicating the development of DKA-CE. BWC for various treatment groups is illustrated in $a$. The DKA treatment group that received bicarbonate and insulin therapy was the only group to significantly increase brain water above control, indicating development of DKA-CE (Kruskal-Wallis one-way ANOVA on ranks followed by Student-NewmanKeuls multiple comparison test, $* p<0.05$ ). Photomicrographs of both a control mouse brain $(b)$ and a mouse brain with DKA-CE $(c)$. The DKA-CE mouse received DKA treatment with $\mathrm{NaHCO}_{3}$ and insulin $2 \mathrm{~h}$ earlier. White arrows show normal pial blood vessels in control, whereas black arrows indicate distorted anatomical fissures in DKA-CE. Scale bars are approximately $2 \mathrm{~mm}$.

BWC was measured as an indicator of DKA-CE after rehydration \pm insulin therapy (Fig. $3 A ; n=23$ /group). The BWC of DKA mice was $3.43 \pm 0.05 \mathrm{~L} / \mathrm{kg}$, significantly lower than the control BWC $(3.72 \pm 0.01 \mathrm{~L} / \mathrm{kg})$. DKA mice treated with saline rehydration had a BWC of $3.65 \pm 0.01 \mathrm{~L} / \mathrm{kg}$, while DKA mice treated with a bicarbonate rehydration solution was $3.64 \pm 0.03 \mathrm{~L} / \mathrm{kg}$. DKA mice treated with saline and insulin had a BWC of $3.71 \pm 0.02 \mathrm{~L} / \mathrm{kg}$. Significantly, the BWC of DKA mice treated with bicarbonate and insulin increased well above control $(3.80 \pm 0.02 \mathrm{~L} / \mathrm{kg})$, indicating development of DKA-CE. Following deep anesthesia and removal of overlying tissues, DKA-CE in situ was observed through the transparent immature skull in DKA mice treated with bicarbonate and insulin (Fig. 3C). The brains of DKA-CE mice were pale in appearance and had distorted fissures with less apparent pial blood vessels, compared with brains of control (Fig. 3B).

In a subgroup of animals, effective osmolalities were calculated for each treatment group (Table 2). Effective osmolality was significantly different in groups treated with rehydration alone (saline $320 \pm 2 \mathrm{mOsmol}$ and bicarbonate $317 \pm 3$ mOsmol) versus those treated with rehydration and insulin (saline and insulin $303 \pm 2 \mathrm{mOsmol}$; bicarbonate and insulin 
Table 2. Blood sodium, glucose, and effective osmolality values for treated DKA mice

\begin{tabular}{lcrr}
\hline \multicolumn{1}{c}{ Therapeutic treatment } & Sodium $(\mathrm{mmol} / \mathrm{L})$ & Glucose $(\mathrm{mmol} / \mathrm{L})$ & Effective osmolality $(\mathrm{mOsmol})$ \\
\hline $\mathrm{NaCl}(77 \mathrm{mmol} / \mathrm{L})$ & $144 \pm 2$ & $31.4 \pm 0.8$ & $320 \pm 2$ \\
$\mathrm{NaCl}(77 \mathrm{mmol} / \mathrm{L})+$ insulin $(1 \mathrm{U} \mathrm{R} / 1 \mathrm{U} \mathrm{NPH})$ & $148 \pm 2$ & $7.8 \pm 3.5$ & $303 \pm 2$ \\
$\mathrm{NaHCO}_{3}(77 \mathrm{mmol} / \mathrm{L})$ & $142 \pm 2$ & $29.8 \pm 0.9$ & $317 \pm 3$ \\
$\mathrm{NaHCO}_{3}(77 \mathrm{mmol} / \mathrm{L})+$ Insulin $(1 \mathrm{U} \mathrm{R} / 1 \mathrm{U} \mathrm{NPH})$ & $149 \pm 1$ & $7.6 \pm 3.5$ & $307 \pm 4$ \\
\hline
\end{tabular}

All groups represent an $n=12$. Effective osmolalities were calculated by $\left[\mathrm{Na}^{+}(\mathrm{mmol} / \mathrm{L}) \times 2\right]+$ glucose $(\mathrm{mmol} / \mathrm{L})$. All treatment groups received $3 \mathrm{ml}$ of rehydration fluid. There are significant differences between DKA mice treated with rehydration only $\left(\mathrm{NaCl}\right.$ or $\left.\mathrm{NaHCO}_{3}\right)$ and those groups treated with rehydration and insulin $\left(\mathrm{NaCl}+\right.$ insulin or $\mathrm{NaHCO}_{3}+$ insulin). There was no significant difference between the two groups that were treated with rehydration and insulin $\left(\mathrm{NaCl}+\right.$ insulin or $\mathrm{NaHCO}_{3}+$ insulin). ANOVA with Student-Newman-Keuls multiple comparison test, $p<0.05$.

$307 \pm 3 \mathrm{mOsmol})$. There was no significant difference in effective osmolality between DKA mice treated with saline and insulin or bicarbonate and insulin. Despite the same effective osmolality between the treatment groups that received insulin, only DKA mice treated with bicarbonate and insulin developed DKA-CE.

Microscopic examination of paraffin-sectioned DKA-CE brain sections, obtained from DKA mice that received bicarbonate and insulin therapy, revealed edema in the perivascular and perineuronal spaces as well as microvacuolation in the white matter tracts, compared with control brains $(n=3$ mice/group). These neuropathological findings were most prevalent in the basal ganglia (Fig. 4), although, subtle differ-

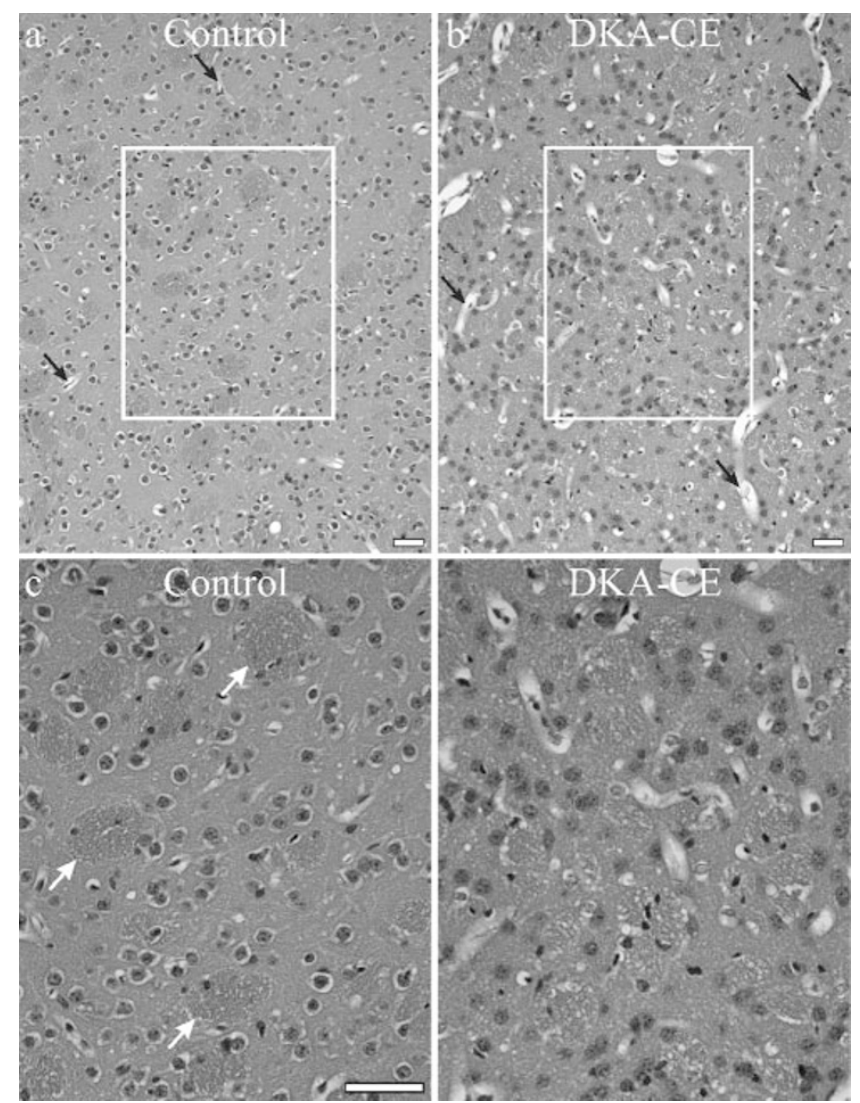

Figure 4. DKA-CE is evident in a tissue section of the striatum obtained from a DKA mouse treated with bicarbonate and insulin. At low magnification, swelling of perivascular spaces (black arrows) and perineuronal spaces is evident in DKA-CE $(b)$ but not control (a) brain slices. At higher magnification, microvacuolation of the white matter tracts (white arrows) was observed in DKA-CE $(d)$ but not control brains $(c)$. ences in both perineuronal and perivascular edema in cortical and hippocampal regions of the DKA-CE brains were also observed (data not shown).

\section{DISCUSSION}

In this study, juvenile mice were briefly fed a high fat diet and injected with STZ/ALX on postnatal d 35, around the time of puberty for C57BL/6 mice (18). Published DKA models use adult animals and vary considerably depending on the species, the pancreatic toxin used, the route of drug administration, and the dosage (10). The prevalent DKA model uses adult rats injected with STZ $(45-200 \mathrm{mg} / \mathrm{kg})(14,19,20)$. DKA was also observed in adult rats $48 \mathrm{~h}$ after injection with ALX (21), and in adult rabbits and dogs injected with STZ/ALX $(22,23)$. The only mouse study to demonstrate ketosis involved STZ-treated adult mice fed a high-fat diet for $16 \mathrm{wk}$ (24). We characterized a juvenile mouse model of DKA, as DKA-CE is almost exclusively a pediatric pathology $(2,25)$. To elicit DKA in juvenile mice, we used STZ/ALX. STZ damages $\beta$-cells via oxidant stress and DNA alkylation (10), whereas ALX toxicity involves oxidation of thiol groups, inhibition of glucokinase, free radical generation, and disturbances in intracellular calcium homeostasis (26). Both STZ and ALX were required to induce DKA in our mice, likely due to rapid $\beta$-cell turnover in juvenile rodents (27). It is unlikely that administration of STZ/ALX directly contributed to the development of DKA-CE, as these pancreatic toxins do not significantly affect brain physiology with acute systemic exposure (28-31).

Immature rats rarely develop ketosis in STZ-induced diabetes (20), likely due to insufficient body fat stores and/or resistance to fat metabolism (32). To increase the probability that our juvenile mice would develop ketosis, we fed our juvenile mice a high-fat diet before injecting them with STZ/ ALX. Seventy-two hours after injection, elevated serum $\beta$-OH-butyrate was measured within the range of $\beta$-OHbutyrate values reported from children with DKA $(11,33)$. Moreover, serum leptin was reduced in untreated DKA mice as observed in children with type- 1 diabetes presenting with DKA (17). In contrast, leptin increases in untreated DKA in both human adults and in an adult mouse model of diabetes (24,34).

Juvenile mice injected with STZ/ALX lost weight and developed osmotic diuresis, anorexia, lethargy, and dehydration. Moreover, biochemical analysis of serum obtained from DKA mice revealed hyperosmolar ketoacidosis associated 
with severe insulin deficiency. Our results demonstrate that STZ/ALX injection in juvenile mice results in a pattern of symptoms and biochemical abnormalities that are similar to that of DKA in children with type 1 diabetes. Glucose and $\beta$-OH-butyrate levels corrected with rehydration and insulin therapy.

DKA-CE in children can develop within hours after starting DKA treatment $(4,5)$, however, DKA-CE has also been observed with imaging in children upon DKA presentation (4,5,35-37). The causes of DKA-CE before therapy are not known but might be related to free water consumption by children with DKA before presentation to hospital (35). Free water was not actively administered to the DKA mice in our study, which could explain the significantly lower BWC than control mice. Our model therefore examined only DKA-CE associated with DKA treatment $(5,6,8)$. Of note, the DKA treatments in this study were administered as a single i.p. injection and may have resulted in more rapid intravascular expansion than would occur clinically with controlled i.v. treatment. Nonetheless, when DKA mice were treated with either saline or bicarbonate rehydration solution, BWC was not significantly different from either control or DKA. The BWC increased to control levels, however, when saline rehydration was combined with insulin therapy. This latter result is probably not clinically significant, as the fixed volume within the intracranial vault should accommodate a BWC up to control levels. The only treatment group to develop significant DKA-CE, defined as a significant increase BWC over control levels, was DKA mice that received combined insulin and bicarbonate therapy.

The DKA-CE observed with combined bicarbonate and insulin therapy reflects both overhydration of the cerebral parenchyma (3) and direct cellular swelling (7). Indeed, edema was evident in both the perineuronal and perivascular spaces and as microvacuolation of the white matter tracts. These neuropathological changes were most prevalent in the basal ganglia, a finding that correlates with imaging studies on children with DKA-CE $(38,39)$.

Decreases in effective osmolality did not correlate with increases in BWC above control values. Effective osmolality significantly decreased in DKA mice that received rehydration and insulin, compared with the groups that received only rehydration. The effective osmolalities of the treatment groups that received saline and insulin or bicarbonate and insulin were not significantly different, yet DKA-CE only occurred when a combination of bicarbonate and insulin were administered. Although the development of DKA-CE in this study did not correlate with decreases in effective osmolality, rapid decreases in effective osmolality would exacerbate DKA-CE (7).

Bicarbonate administration in DKA might cause a paradoxical acidosis in brain, as systemic bicarbonate therapy elevates serum $\mathrm{CO}_{2}$ that rapidly diffuses across the blood brain barrier (40). Rapid acidosis in brain secondary to $\mathrm{CO}_{2}$ accumulation may elicit DKA-CE, perhaps via hyperemia from the acid altering effects on cerebral blood flow (41). Cerebral hypoxia may also occur from bicarbonate administration in DKA (23). If the DKA-CE elicited in this study with combined bicarbonate and insulin therapy was specifically due to paradoxical acidosis in brain and/or cerebral hypoxia, then the DKA mice treated with bicarbonate alone should have also developed DKA-CE. As the BWC was not significantly elevated in the bicarbonate group, additional mechanisms specific to insulin must contribute to DKA-CE. Indeed, plasma bicarbonate and $\mathrm{pH}$ markedly affect the dissolution of insulin and, hence, the bioavailability of the active insulin monomer (42).

These animal data suggest that bicarbonate should not be used to correct the metabolic acidosis in children receiving insulin therapy for DKA. Bicarbonate therapy does not improve the outcome of severe DKA (43) and an association between bicarbonate administered to children with DKA and the subsequent development of DKA-CE has been suggested (5). This adverse relationship between bicarbonate and DKA-CE had not been reproduced experimentally in juvenile animals, however, as we have done in this report. The finding that BWC was elevated in DKA mice treated with bicarbonate and insulin suggests that rapid systemic alkalinization may exacerbate brain swelling, but requires priming with insulin. The precipitating factors that predispose children to DKA-CE in the absence of bicarbonate administration remain unclear, but may include a combination of factors, including cerebral edema on presentation, insulin administration and rapid correction in systemic $\mathrm{pH}$.

In summary, we have characterized a juvenile mouse model of DKA that develops symptoms and biochemical changes that are similar to those observed in children with DKA. DKA was corrected in mice by rehydration and insulin therapy. Moreover, our data demonstrate the potential adverse outcome of DKA-CE with combined insulin and bicarbonate therapy. As always, caution must be exercised with extrapolation of animal data to humans, although further experiments using this mouse model may help clarify the causes of DKA-CE and lead to the identification of safer therapeutic maneuvers and/or pharmacological targets for neuroprotection.

Acknowledgments. The authors thank Drs. Desmond Bohn and Ram Singh for constructive comments on this manuscript. We also thank Dr. David Ramsay (Neuropathology), Jinming Li (ELISA), Karen Nygard (technical support), and Jamie Seabrook (Biostatistician).

\section{REFERENCES}

1. Rosenbloom AL, Schatz DA, Krischer JP, Skyler JS, Becker DJ, Laporte RE, Libman I, Pietropaolo M, Dosch HM, Finberg L, Muir A, Tamborlane WV, Grey M, Silverstein JH, Malone JI 2000 Therapeutic controversy: prevention and treatment of diabetes in children. J Clin Endocrinol Metab 85:494-522

2. Chiasson JL, Aris-Jilwan N, Belanger R, Bertrand S, Beauregard H, Ekoe JM, Fournier H, Havrankova J 2003 Diagnosis and treatment of diabetic ketoacidosis and the hyperglycemic hyperosmolar state. CMAJ 168:859-866

3. Dunger DB, Sperling MA, Acerini CL, Bohn DJ, Daneman D, Danne TP, Glaser NS, Hanas R, Hintz RL, Levitsky LL, Savage MO, Tasker RC, Wolfsdorf JI 2004 ESPE/LWPES consensus statement on diabetic ketoacidosis in children and adolescents. Arch Dis Child 89:188-194

4. Lawrence SE, Cummings EA, Gaboury I, Daneman D 2005 Population-based study of incidence and risk factors for cerebral edema in pediatric diabetic ketoacidosis. J Pediatr 146:688-692

5. Glaser N, Barnett P, McCaslin I, Nelson D, Trainor J, Louie J, Kaufman F, Quayle K, Roback M, Malley R, Kuppermann N 2001 Risk factors for cerebral edema in children with diabetic ketoacidosis. The Pediatric Emergency Medicine Collaborative Research Committee of the American Academy of Pediatrics. N Engl J Med 344:264-269

6. Carlotti AP, Bohn D, Halperin ML 2003 Importance of timing of risk factors for cerebral oedema during therapy for diabetic ketoacidosis. Arch Dis Child 88:170-173

7. Bohn D, Daneman D 2002 Diabetic ketoacidosis and cerebral edema. Curr Opin Pediatr 14:287-291 
8. Edge JA 2000 Cerebral oedema during treatment of diabetic ketoacidosis: are we any nearer finding a cause? Diabetes Metab Res Rev 16:316-324

9. Marcin JP, Glaser N, Barnett P, McCaslin I, Nelson D, Trainor J, Louie J, Kaufman F, Quayle K, Roback M, Malley R, Kuppermann N 2002 Factors associated with adverse outcomes in children with diabetic ketoacidosis-related cerebral edema. J Pediatr 141:793-797

10. Szkudelski T 2001 The mechanism of alloxan and streptozotocin action in B cells of the rat pancreas. Physiol Res 50:537-546

11. Clarke WL, Cox D, Gonder-Frederick LA, Carter W, Pohl SL 1987 Evaluating clinical accuracy of systems for self-monitoring of blood glucose. Diabetes Care 10:622-628

12. Ham MR, Okada P, White PC 2004 Bedside ketone determination in diabetic children with hyperglycemia and ketosis in the acute care setting. Pediatr Diabetes 5:39-43

13. Byrne HA, Tieszen KL, Hollis S, Dornan TL, New JP 2000 Evaluation of an electrochemical sensor for measuring blood ketones. Diabetes Care 23:500-503

14. Silver SM, Clark EC, Schroeder BM, Sterns RH 1997 Pathogenesis of cerebral edema after treatment of diabetic ketoacidosis. Kidney Int 51:1237-1244

15. Bloch O, Papadopoulos MC, Manley GT, Verkman AS 2005 Aquaporin-4 gene deletion in mice increases focal edema associated with staphylococcal brain abscess. J Neurochem 95:254-262

16. Loeb WF, Quimby FW 1999 The Clinical Chemistry of Laboratory Animals. Taylor \& Francis, Philadelphia

17. Hathout EH, Sharkey J, Racine M, Ahn D, Mace JW, Saad MF 1999 Changes in plasma leptin during the treatment of diabetic ketoacidosis. J Clin Endocrinol Metab $84: 4545-4548$

18. Aiello S, Mays A 1998 The Merck Veterinary Manual. Merck \& Co., in cooperation with Merial Limited, Whitehouse Station, NJ

19. Harris GD, Lohr JW, Fiordalisi I, Acara M 1993 Brain osmoregulation during extreme and moderate dehydration in a rat model of severe DKA. Life Sci 53:185-191

20. Forster O, Rudas B 1969 Ketosis in rats with streptozotocin-induced diabetes. Lancet $1: 1321-1322$

21. Miethke H, Wittig B, Nath A, Jungermann K 1986 Gluconeogenic-glycolytic capacities and metabolic zonation in liver of rats with streptozotocin, non-ketotic as compared to alloxan, ketotic diabetes. Histochemistry 85:483-489

22. Harris GD, Fiordalisi I, Yu C 1996 Maintaining normal intracranial pressure in a rabbit model during treatment of severe diabetic ketoacidemia. Life Sci 59:1695-1702

23. Bureau MA, Begin R, Berthiaume Y, Shapcott D, Khoury K, Gagnon N 1980 Cerebral hypoxia from bicarbonate infusion in diabetic acidosis. J Pediatr 96:968-973

24. Polotsky VY, Wilson JA, Haines AS, Scharf MT, Soutiere SE, Tankersley CG, Smith PL, Schwartz AR, O'Donnell CP 2001 The impact of insulin-dependent diabetes on ventilatory control in the mouse. Am J Respir Crit Care Med 163:624-632

25. Kitabchi AE, Umpierrez GE, Murphy MB, Barrett EJ, Kreisberg RA, Malone JI, Wall BM 2001 Management of hyperglycemic crises in patients with diabetes. Diabetes Care 24:131-153
26. Mathews CE, Leiter EH 1999 Constitutive differences in antioxidant defense status distinguish alloxan-resistant and alloxan-susceptible mice. Free Radic Biol Med 27:449-455

27. Trudeau JD, Dutz JP, Arany E, Hill DJ, Fieldus WE, Finegood DT 2000 Neonatal beta-cell apoptosis: a trigger for autoimmune diabetes? Diabetes 49:1-7

28. Moreira PI, Santos MS, Moreno AM, Proenca T, Seica R, Oliveira CR 2004 Effect of streptozotocin-induced diabetes on rat brain mitochondria. J Neuroendocrinol $16: 32-38$

29. Sanders NM, Dunn-Meynell AA, Levin BE 2004 Third ventricular alloxan reversibly impairs glucose counterregulatory responses. Diabetes 53:1230-1236

30. Shoham S, Bejar C, Kovalev E, Weinstock M 2003 Intracerebroventricular injection of streptozotocin causes neurotoxicity to myelin that contributes to spatial memory deficits in rats. Exp Neurol 184:1043-1052

31. Ramakrishnan R, Nazer MY, Suthanthirarajan N, Namasivayam A 2003 An experimental analysis of the catecholamines in hyperglycemia and acidosis induced rat brain. Int J Immunopathol Pharmacol 16:233-239

32. McGarry JD, Foster DW 1977 Hormonal control of ketogenesis. Biochemical considerations. Arch Intern Med 137:495-501

33. Nadgir UM, Silver FL, MacGillivray MH 2001 Unrecognized persistence of betahydroxybutyrate in diabetic ketoacidosis. Endocr Res 27:41-46

34. Nakamura T, Nagasaka S, Ishikawa S, Fujibayashi K, Kawakami A, Rokkaku K, Hayashi H, Saito T, Kusaka I, Higashiyama M 1999 Serum levels of leptin and changes during the course of recovery from diabetic ketoacidosis. Diabetes Res Clin Pract 46:57-63

35. Fiordalisi I, Harris GD, Gilliland MG 2002 Prehospital cardiac arrest in diabetic ketoacidemia: why brain swelling may lead to death before treatment. J Diabetes Complications 16:214-219

36. Hoffman WH, Steinhart CM, el Gammal T, Steele S, Cuadrado AR, Morse PK 1988 Cranial CT in children and adolescents with diabetic ketoacidosis. AJNR Am J Neuroradiol 9:733-739

37. Durr JA, Hoffman WH, Sklar AH, el Gammal T, Steinhart CM 1992 Correlates of brain edema in uncontrolled IDDM. Diabetes 41:627-632

38. Glaser NS, Wootton-Gorges SL, Marcin JP, Buonocore MH, Dicarlo J, Neely EK, Barnes P, Bottomly J, Kuppermann N 2004 Mechanism of cerebral edema in children with diabetic ketoacidosis. J Pediatr 145:164-171

39. Muir AB, Quisling RG, Yang MC, Rosenbloom AL 2004 Cerebral edema in childhood diabetic ketoacidosis: natural history, radiographic findings, and early identification. Diabetes Care 27:1541-1546

40. Posner JB, Plum F 1967 Spinal-fluid pH and neurologic symptoms in systemic acidosis. N Engl J Med 277:605-613

41. Tasker RC, Lutman D, Peters MJ 2005 Hyperventilation in severe diabetic ketoacidosis. Pediatr Crit Care Med 6:405-411

42. Fischer U, Lougheed WD, Albisser AM 1989 In vivo bicarbonate deficiency and insulin dissolution. ASAIO Trans 35:26-29

43. Green SM, Rothrock SG, Ho JD, Gallant RD, Borger R, Thomas TL, Zimmerman GJ 1998 Failure of adjunctive bicarbonate to improve outcome in severe pediatric diabetic ketoacidosis. Ann Emerg Med 31:41-48 